\title{
Modeling Alpha-Band Functional Connectivity for MEG Resting State Data: Oscillations and Delays in a Spiking Neuron Model
}

Tristan T Nakagawa ${ }^{1 *}$, Henry Luckhoo ${ }^{2}$, Mark Woolrich², Morten Joensson ${ }^{3,4}$, Hamid Mohseni ${ }^{3}$, Morten Kringelbach², Viktor Jirsa ${ }^{5}$, Gustavo Deco ${ }^{6}$

From Twenty Second Annual Computational Neuroscience Meeting: CNS*2013

Paris, France. 13-18 July 2013

The study of structural and functional connectivity (SC, FC) and dynamics in spontaneous brain activity is a rapidly growing field of research [1]. The existence of Resting State Networks (RSN) has been well established in fMRI over the past decade, [1] and computational models [2] have successfully captured their connectivity patterns and slow oscillations, but have not been applied to recent MEG findings of coherent RSN [3] yet.

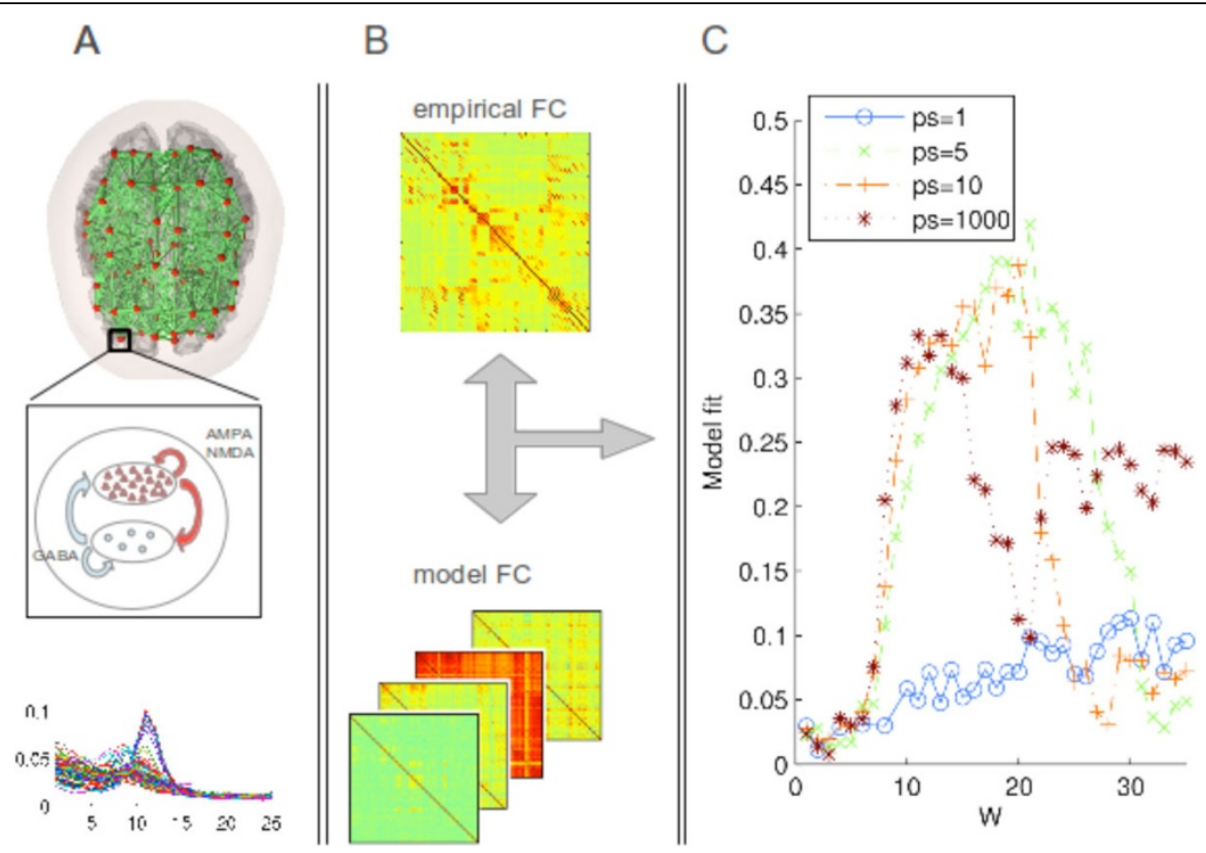

Figure 1 A: Sketch of the global model graph, each node consisting of local populations of spiking neurons. The model is capable of producing alpha oscillations (bottom). B: Empirical and simulated FC are fitted and C: the model best captures the empirical pattern with physiological delays $(p s=5-10 \mathrm{~m} / \mathrm{s})$.

\footnotetext{
* Correspondence: tristan.nakagawa@upf.edu

'Department of Technology, Universitat Pompeu Fabra, Barcelona, Spain

Full list of author information is available at the end of the article
} 
Here, we extended a recent neurophysiologically realistic spiking-neuron model of spontaneous fMRI activity [4] to exhibit noisy oscillatory activity in the alpha band (Figure 1A, bottom) and studied how connectivity and delays influenced the model fit with the oscillatory MEG FC. The global network was described by a graph of nodes (local populations of excitatory and inhibitory spiking neurons), connected to each other according to a DTI-derived anatomical connectivity matrix, which fixed the relative connectivity and delay/distance structure, but left global scaling factors $\mathrm{W}$ (coupling weight) and ps (propagation speed in $\mathrm{m} / \mathrm{s}$ ) as free parameters in the model. FC was measured by correlating the low-pass filtered Power Envelopes of the bandlimited signal. Simulations showed the largest margin of good concordance with empirical FC over W when neurophysiologically realistic delays $(5-10 \mathrm{~m} / \mathrm{s})$ were included (Figure $1 \mathrm{C})$.

\section{Conclusions}

In the presence of noisy oscillations on the same order of magnitude as system delays, the temporal connectivity structure plays a role in shaping the functional network connectivity. By effectively decreasing strong synchronous inputs to nodes, the network is stabilized and the need for fine-tuning of global coupling reduced when compared to the absence of delays.

\section{Author details}

Department of Technology, Universitat Pompeu Fabra, Barcelona, Spain. ${ }^{2}$ Centre for Human Brain Activity, University of Oxford, Oxford, UK. ${ }^{3}$ Department of Psychiatry, University of Oxford, Oxford, UK. ${ }^{4} \mathrm{FCIN}$, Aarhus University, Denmark. ${ }^{5}$ CNRS, Université de la Méditeranée, Marseille, France.

${ }^{6}$ ICREA, Barcelona, Spain.

Published: 8 July 2013

\section{References}

1. Lang EW, Tomé AM, Keck IR, Górriz-Sáez JM, Puntonet CG: Brain Connectivity Analysis: A Short Survey. Comput Intell Neurosci 2012, 2012:1-21.

2. Deco G, Jirsa VK, McIntosh AR: Emerging concepts for the dynamical organization of resting-state activity in the brain. Nat Rev Neurosci 2011, 12:43-56.

3. Brookes MJ, Woolrich M, Luckhoo H, Price D, Hale JR, Stephenson MC, Barnes GR, Smith SM, Morris PG: Investigating the electrophysiological basis of resting state networks using magnetoencephalography. Proceedings of the National Academy of Sciences 2011.

4. Deco G, Jirsa VK: Ongoing Cortical Activity at Rest: Criticality, Multistability, and Ghost Attractors. J Neurosci 2012, 32:3366-3375.

doi:10.1186/1471-2202-14-S1-P99

Cite this article as: Nakagawa et al:: Modeling Alpha-Band Functional Connectivity for MEG Resting State Data: Oscillations and Delays in a Spiking Neuron Model. BMC Neuroscience 2013 14(Suppl 1):P99.

\section{Submit your next manuscript to BioMed Central} and take full advantage of:

- Convenient online submission

- Thorough peer review

- No space constraints or color figure charges

- Immediate publication on acceptance

- Inclusion in PubMed, CAS, Scopus and Google Scholar

- Research which is freely available for redistribution

Submit your manuscript at www.biomedcentral.com/submit
C BioMed Central 